\title{
Effect of inter-pregnancy interval on maternal and fetal outcome
}

\author{
Pravin Shrestha, Vibha Mahato, Smita Karmacharya \\ Department of Obstetrics and Gynaecology \\ Manipal College of Medical Sciences, Pokhara, Nepal
}

Received: May 1, $2020 \quad$ Accepted: May 15, 2020

\begin{abstract}
Aims: To explore the impact of inter-pregnancy interval on maternal and fetal health

Methods: Descriptive cross sectional study conducted at Department of Obstetrics and Gynaecology, Manipal Teaching hospital, Pokhara, Nepal. Inter-pregnancy interval (IPI) was calculated as the time elapsed between the woman's last delivery and the date of last menstrual period for the present second or higher order birth. Intervals were taken in weeks and then converted to months. IPI were categorized as $<18$ months, 18-23, 24-59, $>59$ months.

Results: Among the 550 pregnancies studied, the majority (57\%) of them had an IPI of more than 59 months. Long IPI of $>59$ months had increased risk of maternal complications like preeclampsia (12.4\%), postdate pregnancy (10.8\%), PROM (4.4\%), oligohydramnios (3.8\%), placenta previa (2.5\%), gestational diabetes mellitus $(2.2 \%)$, chronic hypertension $(1.5 \%)$, abruptio placenta $(0.3 \%)$, IUFD $(0.6 \%)$ and overt DM $(0.3 \%)$. Increased preterm birth was seen in IPI $<18$ months $(25 \%)$. Short IPI had also increased risk of IUGR $(8.3 \%)$ and anaemia. Adverse maternal outcome was least when IPI was between 18-23 months.
\end{abstract}

Conclusions: IPI shorter than 18 months and longer than 59 months were associated with increased risk of adverse maternal and perinatal outcomes.

Keywords: fetal, inter-pregnancy, interval

Citation : Shrestha P, Mahato V, Karmacharya S. Effect of inter-pregnancy interval on maternal and fetal outcome. Nep J Obstet Gynecol 2020;15(30): 58-61. DOI: 10.3126/njog.v15i1.29343

\section{INTRODUCTION}

The optimal time to conceive another pregnancy is one of the frequently asked questions to an obstetrician. The time between the end of a pregnancy and the start of another is defined as inter-pregnancy interval (IPI). ${ }^{1}$ As per WHO, after a live birth, the recommended interval before attempting the next pregnancy is at least 24 months in order to reduce the risk of adverse maternal, perinatal and infant outcomes. ${ }^{2}$

Studies showed that intervals of less than 18 and greater than 59 months were associated with higher risks of preterm, low-birth-weight and small for gestational age babies. ${ }^{3}$ Women in high resource nations are increasingly delaying childbearing which poses challenges for spacing of pregnancies. ${ }^{4}$ Short IPI increases the risk of premature rupture of membrane (PROM), placental abruption, placenta praevia, uterine rupture (for women who previously delivered by caesarean section) and gestational diabetes (GDM) ${ }^{5-10}$ Similarly, long IPIs have been associated with increased risk of pre-eclampsia and labour dystocia. ${ }^{11-13}$

The effect of IPI on maternal and fetal health has not received much attention in our settings. So this study may be helpful in counselling couples for planning an optimal time to conceive another pregnancy in order to have the best possible pregnancy outcomes.

\section{METHODS}

This is an observational cross sectional study conducted at department of Obstetrics and Gynaecology, Manipal Teaching Hospital, Pokhara, Nepal from August 2018 to February 2020 after IRC approval from the institution and consent from patients. Cases

\section{CORRESPONDENCE}

Dr Pravin Shrestha

Department of Obstetrics and Gynaecology

Manipal College of Medical Sciences, Pokhara, Nepal

Email: pravinstha3@gmail.com; Mobile: +977-9846111847 
with two or more consecutive pregnancies, previous live baby and singleton pregnancy were included; and multifetal pregnancy and history of miscarriage prior to index pregnancy were excluded.

Inter-pregnancy interval was calculated as the time elapsed between the woman's last delivery and the date of last menstrual period; and categorized as shorter to longer intervals $<18,18-23,24-59$ and $>59$ months. Variables studied were age at conception of the index pregnancy, number of prior births and period of gestation, mode of delivery; preeclampsia, eclampsia, placenta previa, abruption placenta, PROM, GDM, post-dated pregnancy, anaemia, postpartum haemorrhage and postpartum psychosis; and preterm birth, low birth weight, Apgar score at five minute, neonatal intensive care unit (NICU) admission and neonatal mortality. The data were recorded in a predesigned proforma and entered in excel sheet. The analysis was done using statistical package for social sciences (SPSS) version 16.

\section{RESULTS}

There were 550 pregnancies in the study and the majority had inter-pregnancy interval of 5 years or more with less in less than 18 months; 18\% (56) had preterm delivery in long spacing where as $25 \%$ in short interval [Table-1].

Table-1: Inter-pregnancy intervals (IPI) by age group, parity and period of gestation

\begin{tabular}{|c|c|c|c|c|c|}
\hline \multicolumn{2}{|c|}{ IPI in months } & $\begin{array}{l}<18 \\
(n=12 \\
2 \%)\end{array}$ & $\begin{array}{l}18-23 \\
(n=37 \\
7 \%)\end{array}$ & $\begin{array}{l}24-59 \\
(n=187 \\
34 \%)\end{array}$ & $\begin{array}{l}>59 \\
(n=314 ; \\
57 \%)\end{array}$ \\
\hline \multirow{3}{*}{$\begin{array}{l}\text { Age in } \\
\text { years }\end{array}$} & $<19$ & 2 & 0 & 2 & 0 \\
\hline & $20-34$ & 9 & 31 & 163 & 258 \\
\hline & $>35$ & 1 & 6 & 22 & 56 \\
\hline \multirow{3}{*}{$\begin{array}{l}\text { Previous } \\
\text { birth }\end{array}$} & 1 & 11 & 29 & 138 & 214 \\
\hline & 2 & 1 & 5 & 40 & 80 \\
\hline & $>3$ & 0 & 3 & 9 & 20 \\
\hline \multirow{4}{*}{$\begin{array}{l}\text { Period of } \\
\text { gestation } \\
\text { in weeks }\end{array}$} & $<32$ & 1 & 0 & 4 & 15 \\
\hline & $32-36$ & 2 & 2 & 22 & 41 \\
\hline & $37-40$ & 7 & 23 & 129 & 172 \\
\hline & $>40$ & 2 & 12 & 32 & 86 \\
\hline
\end{tabular}

Compared to mothers with Inter-pregnancy interval of 18-23 months, long IPI of $>59$ months had increased risk of preeclampsia $(\mathrm{OR}=11.1 ; 95 \% \mathrm{CI}=$ 0.6-185.3), chronic hypertension ( $\mathrm{OR}=1.3 ; 95 \%$ $\mathrm{CI}=0.07-24.5)$ and third trimester bleeding $(\mathrm{OR}=2.3$; $95 \% \mathrm{CI}=0.1-40)$. GDM was more common in long spacing of more than 59 months $(\mathrm{OR}=1.82 ; 95 \%$ $\mathrm{CI}=0.1-32.6)$. Increased preterm birth was seen in IPI $<18$ months $(\mathrm{OR}=11.1 ; 95 \% \mathrm{CI}=0.6-185.3)$. Short IPI had also increased risk of anaemia $(\mathrm{OR}=27.6 ; 95 \%$ $\mathrm{CI}=1.3-582)$ and IUGR (OR=9.7; 95\% $\mathrm{CI}=0.3-256)$ [Table-2].

Table-2: Antepartum complications with Interpregnancy interval

\begin{tabular}{|c|c|c|c|c|}
\hline $\begin{array}{l}\text { IPI in months } \\
\text { Parameters }\end{array}$ & $\begin{array}{c}<18 \\
(n=12 \\
2 \%)\end{array}$ & $\begin{array}{c}18-23 \\
(n=37 \\
7 \%)\end{array}$ & $\begin{array}{c}24-59 \\
(n=187 \\
34 \%)\end{array}$ & $\begin{array}{c}>59 \\
(n=314 ; \\
57 \%)\end{array}$ \\
\hline Preeclampsia & 0 & 0 & $12(6.4 \%)$ & $39(12.4 \%)$ \\
\hline Eclampsia & 0 & 0 & $1(0.5 \%)$ & $1(0.3 \%)$ \\
\hline Chronic HTN & 0 & 0 & $2(1.06 \%)$ & $5(1.59 \%)$ \\
\hline Placenta Previa & 0 & 0 & $4(2.1 \%)$ & $8(2.5 \%)$ \\
\hline Abruptio placenta & 0 & 0 & 0 & $1(0.3 \%)$ \\
\hline Overt DM & 0 & 0 & 0 & $1(0.3 \%)$ \\
\hline GDM & 0 & 0 & $1(0.5 \%)$ & $7(2.2 \%)$ \\
\hline Preterm labour & $3(25 \%)$ & $2(5.4 \%)$ & $26(13.9 \%)$ & $56(17.8 \%)$ \\
\hline PROM & 0 & $1(2.7 \%)$ & $6(3.2 \%)$ & $14(4.4 \%)$ \\
\hline Oligohydramnios & 0 & 0 & $5(2.6 \%)$ & $12(3.8 \%)$ \\
\hline Postdate & 0 & $3(8.1 \%)$ & $13(6.9 \%)$ & $34(10.8 \%)$ \\
\hline IUGR & $1(8.3 \%)$ & $1(2.7 \%)$ & $7(3.7 \%)$ & $7(2.2 \%)$ \\
\hline Anaemia & $3(25 \%)$ & 0 & 0 & 0 \\
\hline IUFD & 0 & 0 & 0 & $2(0.6 \%)$ \\
\hline Ruptured uterus & 0 & 0 & $1(0.5 \%)$ & 0 \\
\hline
\end{tabular}

Caesarean section rate was increasing with increasing birth spacing. Indications were non progress of labour, previous LSCS, severe preeclampsia and antepartum haemorrhage. [Table-3].

Table-3: Mode of delivery by IPI

\begin{tabular}{|c|c|c|c|c|}
\hline $\begin{array}{l}\text { IPI in months } \\
\text { Mode }\end{array}$ & $\begin{array}{c}<18 \\
(\mathrm{n}=12 \\
2 \%)\end{array}$ & $\begin{array}{c}18-23 \\
(\mathrm{n}=37 \\
7 \%)\end{array}$ & $\begin{array}{c}24-59 \\
(n=187 \\
34 \%)\end{array}$ & $\begin{array}{c}>59 \\
(n=314 ; \\
57 \%)\end{array}$ \\
\hline Vaginal & $\begin{array}{c}10 \\
(83.3 \%)\end{array}$ & $\begin{array}{c}31 \\
(83.7 \%)\end{array}$ & $\begin{array}{c}112 \\
(59.8 \%)\end{array}$ & $\begin{array}{c}182 \\
(57.9 \%)\end{array}$ \\
\hline LSC & $\begin{array}{c}2 \\
(16.6 \%)\end{array}$ & $\begin{array}{c}6 \\
(16.2 \%)\end{array}$ & $\begin{array}{c}75 \\
(40.2 \%)\end{array}$ & $\begin{array}{c}132 \\
(42.1 \%)\end{array}$ \\
\hline
\end{tabular}


Postpartum Haemorrhage was more in women with short IPI $(8.3 \%)$. Two women $(0.6 \%)$ with long IPI had peripartum hysterectomy [Table-4].

Table-4: Postpartum complications by inter-pregnancy interval

\begin{tabular}{|l|c|c|c|c|}
\hline $\begin{array}{l}\text { IPI in months } \\
\text { Parameters }\end{array}$ & $\begin{array}{c}<\mathbf{1 8} \\
(\mathbf{n = 1 2} ; \\
\mathbf{2 \%})\end{array}$ & $\begin{array}{c}\mathbf{1 8 - 2 3} \\
(\mathbf{n}=\mathbf{3 7} ;\end{array}$ & $\begin{array}{c}\mathbf{2 4 - 5 9} \\
(\mathbf{n}=\mathbf{1 8 7} ;\end{array}$ & $\begin{array}{c}>\mathbf{3 4} \%) \\
(\mathbf{n}=\mathbf{3 1 4} \\
\mathbf{5 7 \%}\end{array}$ \\
\hline PPH & $1(8.3 \%)$ & $1(2.7 \%)$ & $5(2.6 \%)$ & $3(0.9 \%)$ \\
\hline Hysterectomy & 0 & 0 & $1(0.5 \%)$ & $2(0.6 \%)$ \\
\hline UTI & 0 & 0 & $5(2.6 \%)$ & $5(1.5 \%)$ \\
\hline Psychosis & 0 & 0 & 0 & $1(0.3 \%)$ \\
\hline
\end{tabular}

Risk of low birth weight $(<2500 \mathrm{~g})$ babies was higher in short inter-pregnancy interval of less than 18 months $(\mathrm{OR}=8.7$; 95\% $\mathrm{CI}=1.3-56.3)$ and lowest in 18- 23 months interval. NICU admission was also more in $<18$ months $(\mathrm{OR}=15 ; 95 \% \mathrm{CI}=0.6-334)$ [Table-5].

Table-5: Neonatal outcomes by inter-pregnancy intervals

\begin{tabular}{|c|c|c|c|c|c|}
\hline \multicolumn{2}{|c|}{$\begin{array}{l}\text { IPI in months } \\
\text { Parameters }\end{array}$} & $\begin{array}{c}<18 \\
(n=12 ; \\
2 \%)\end{array}$ & $\begin{array}{c}18-23 \\
(n=37 \\
7 \%)\end{array}$ & $\begin{array}{c}24-59 \\
(n=187 \\
34 \%)\end{array}$ & $\begin{array}{c}>59 \\
(n=314 \\
57 \%)\end{array}$ \\
\hline \multirow[t]{3}{*}{ Morbidity } & NICU & $\begin{array}{c}2 \\
(16.6 \%)\end{array}$ & 0 & $\begin{array}{c}16 \\
(8.5 \%)\end{array}$ & $\begin{array}{c}39 \\
(12.4 \%)\end{array}$ \\
\hline & IUFD & 0 & 0 & 0 & $6(1.9 \%)$ \\
\hline & NND & 0 & 0 & $1(0.5)$ & 0 \\
\hline \multirow[t]{2}{*}{$\begin{array}{l}\text { Apgar } \\
\text { score }(<7)\end{array}$} & 1-min & $\begin{array}{c}1 \\
(8.3 \%)\end{array}$ & $\begin{array}{c}1 \\
(2.7 \%)\end{array}$ & $\begin{array}{c}22 \\
(11.7 \%)\end{array}$ & $\begin{array}{c}34 \\
(10.8 \%)\end{array}$ \\
\hline & 5-min & $\begin{array}{c}1 \\
(8.3 \%)\end{array}$ & 0 & $\begin{array}{c}7 \\
(3.7 \%)\end{array}$ & $\begin{array}{c}17 \\
(5.4 \%)\end{array}$ \\
\hline Anomaly & & 0 & 0 & 0 & $4(1.27 \%)$ \\
\hline \multirow{3}{*}{$\begin{array}{l}\text { Fetal } \\
\text { weight } \\
(\mathrm{kg})\end{array}$} & $<2.5$ & $\begin{array}{c}4 \\
(33.3 \%)\end{array}$ & $\begin{array}{c}2 \\
(5.4 \%)\end{array}$ & $\begin{array}{c}32 \\
(17.1 \%)\end{array}$ & $\begin{array}{c}56 \\
(17.8 \%)\end{array}$ \\
\hline & $2.5-4$ & $\begin{array}{c}7 \\
(58.3 \%)\end{array}$ & $\begin{array}{c}35 \\
(94.5 \%)\end{array}$ & $\begin{array}{c}149 \\
(79.6 \%)\end{array}$ & $\begin{array}{c}250 \\
(79.6 \%)\end{array}$ \\
\hline & $>4$ & $1(8.3 \%)$ & 0 & $6(3.2 \%)$ & $8(2.5 \%)$ \\
\hline
\end{tabular}

\section{DISCUSSION}

In our study, the majority $314(57 \%)$ of patients had an inter pregnancy interval of more than 59 months. Long IPI may be due to economic issues or unavailability of partner due to migration for foreign employment. Long IPI of $>59$ months had increased risk of maternal complications like preeclampsia (12.4\%), chronic hypertension(1.5\%), placenta previa (2.5\%), abruptio placenta(0.3\%), PROM $(4.4 \%)$, oligohydramnios $(3.8 \%)$, postdate pregnancy $(10.8 \%)$ and IUFD $(0.6 \%)$. This may be possible due to the physiological regression hypothesis that perinatal outcomes for infants conceived after an excessively long inter-pregnancy interval are similar to infants born to primigravida women. ${ }^{14}$ The rates of pre-eclampsia, eclampsia and gestational diabetes mellitus were highest among women with intervals longer than 59 months. A slight increase in the rates of third trimester bleeding was also seen in women with this inter-pregnancy interval. ${ }^{15}$ Similar findings were seen in our study. Gestational diabetes mellitus was more common among mothers with IPI of more than 59 months $(2.2 \%)$ similar to the findings of Gebremedhin AT et al. ${ }^{16}$

Increased preterm birth was seen in IPI $<18$ months $(25 \%)$. Short IPI had also increased risk of IUGR $(8.3 \%)$ and anaemia $(25 \%)$ which may be explained by the folate depletion hypothesis. Woman who conceives before restoration of folate, erythrocytes has higher risks of preterm birth, IUGR and anaemia. ${ }^{17}$ Similar findings of increased preterm birth and IUGR were seen in the study done by Smith GC et al. ${ }^{18}$

Of the new-born babies the risk of low birth weight was higher among mothers who had short interpregnancy interval of less than 18 months (33.3\%). NICU admissions were more when IPI was $<18$ months $(16.6 \%)$ most probably due to preterm births and IUGR babies.

This is similar to the study done by Bener A et al that women with short birth intervals are at increased risk of low birth weight. ${ }^{19}$ The explanation is the maternal nutritional depletion hypotheses that close succession of pregnancies and lactation worsens the maternal nutritional status as there is lesser time to recover from the physiological stresses of the preceding pregnancy before she is subjected to the stress of the next. ${ }^{20}$ In cases of low birth weight babies, mothers with a birth interval of 18-23 months had the lowest risk $(5.4 \%)$. Zhu BP et al have revealed an apparent optimal inter-pregnancy interval of 18-23 months. ${ }^{21}$

Caesarean Section increased with inter-pregnancy interval in our study with $16.6 \%$ of women delivering 
by LSCS with IPI $<18$ months which increased to $>42.1 \%$ in IPI $>59$ months indications being non progress of labour, previous LSCS, severe preeclampsia and antepartum haemorrhage. Labour dystocia was increased with inter-pregnancy interval in the study done by Zhu BP et al. ${ }^{13}$ Adverse maternal and fetal outcome was least when IPI was between 18-23 months. ${ }^{15,21-23}$

\section{CONCLUSIONS}

Inter-pregnancy interval shorter than 18 months had higher risk of preterm, anemia, IUGR, low birth weight and NICU admission whereas longer than 59 months had higher risk of hypertension, GDM and APH. Increasing birth spacing had increased proportion of Cesarean Section.

\section{REFERENCES}

1. Bentolia Y, Ratzon R, Shoham-vardi I, Serjienko R, Mazor M,Bashiri A. Effect of inter-pregnancy interval on outcome of pregnancy after recurrent pregnancy loss. Matern Fetal Neonatal Med. 2013;26:1459-64

2. Report of a WHO Technical Consultation on Birth Spacing Geneva, Switzerland, 13-15 June2005.

3. Conde-Agudelo A, Rosas-Bermúdez A, Kafury-Goeta AC Birth spacing and risk of adverse perinatal outcomes: a metaanalysis. J Am Med Assoc. 2006;295(15):1809-23.

4. Mathews TJ. Delayed childbearing: more women are having their first child later in life. US Department of Health and Human Services, Centres for Disease Control and Prevention, National Center for Health Statistics; 2009.

5. Getahun D, Strickland D, Ananth CV, Fassett MJ, Sacks DA Kirby RS, et al. Recurrence of preterm premature rupture of membranes in relation to interval between pregnancies. Am J Obstet Gynecol. 2010;202(6):570-e1

6. Razzaque A, Da Vanzo J, Rahman M, Gausia K, Hale L, Khan $\mathrm{MA}$, et al. Pregnancy spacing and maternal morbidity in Matlab, Bangladesh. Int J Gynecol Obstet. 2005;89:S41-9.

7. Getahun D, Oyelese Y, Salihu HM, Ananth CV. Previous cesarean delivery and risks of placenta previa and placental abruption. Obstet Gynecol. 2006;107(4):771-8.

8. Bujold E, Gauthier RJ. Risk of uterine rupture associated with an interdelivery interval between 18 and 24 months. Obstet Gynecol. 2010;115:1003-6.

9. Esposito MA, Menihan CA, Malee MP. Association of interpregnancy interval with uterine scar failure in labor: a casecontrol study. Am J Obstet Gynecol. 2000;183:1180-3.

10. Hanley GE, Hutcheon JA, Kinniburgh BA, Lee L. Interpregnancy interval and adverse pregnancy outcomes. Obstet Gynecol. 2017;129(3):408-15.

11. Harutyunyan A, Armenian H, Petrosyan V. Interbirth interval and history of previous preeclampsia: a case-control study among multiparous women. BMC Pregnancy Childbirth. 2013;13:244

12. Basso O, Christensen $\mathrm{K}$, Olsen J. Higher risk of pre-eclampsia after change of partner. An effect of longer inter-pregnancy intervals? Epidemiology. 2001;12:624-9

13. Zhu BP, Grigorescu V, Le T, Lin M, Copeland G, Barone M, et al. Labor dystocia and its association with inter-pregnancy interval. Am J Obstet Gynecol. 2006;195(1):121-8

14. Zhu BP, Rolfs RT, Nangle BE, Horan JM. Effect of the interval between pregnancies on perinatal outcomes. New Eng $J$ Med. 1999;340(8):589-94.

15. Conde-Agudelo A, Belizán JM. Maternal morbidity and mortality associated with inter-pregnancy interval: cross sectional study. BMJ. 2000;321(7271):1255-9.

16. Gebremedhin AT, Regan AK, Ball S, Betrán AP, Foo D, Gissler M, et al. Effect of inter-pregnancy interval on gestational diabetes: a retrospective matched cohort study. Annal Epidemiolog. 2019;39:33-8.

17. Smits LJ, Essed GG. Short inter-pregnancy intervals and unfavourable pregnancy outcome: role of folate depletion. The Lancet. 2001;358(9298):2074-7.

18. Smith GC, Pell JP, Dobbie R. Inter-pregnancy interval and risk of preterm birth and neonatal death: retrospective cohort study. BMJ. 2003;327(7410):313.

19. Bener A, Saleh NM, Salameh KM, Basha B, Joseph S, Samson $\mathrm{N}$, et al. The impact of the inter-pregnancy interval on birth weight and other pregnancy outcomes. Revista Brasileira de Saúde Materno Infantil. 2012;12(3):233-41.

20. Winkvist A, Rasmussen KM, Habicht JP. A new definition of maternal depletion syndrome. Am J Public Health. $1992 ; 82: 691-4$

21. Zhu BP, Le T. Effect of inter-pregnancy interval on infant low birth weight: a retrospective cohort study using the Michigan Maternally Linked Birth Database. Mat Child Health J. 2003;7(3):169-78.

22. Bhattacharya S, Smith N. Pregnancy following miscarriage: what is the optimum inter-pregnancy interval? Womens Health (Lond). 2011;7:139-41.

23. Conde-Agudelo A, Rosas-Bermudez A, Castano F, Norton MH. Effects of birth spacing on maternal, perinatal, infant, and child health: a systematic review of causal mechanisms. Stud Fam Plann. 2012;43:93-114. 